\title{
A ANÁliSE DE CONTEÚdO DE PRONUNCIAMENTOS OFICIAIS COMO METODOLOGIA INTERPRETATIVA DA POLÍTICA EXTERNA BRASILEIRA $^{1}$
}

\author{
Danielle Costa da Silva ${ }^{2}$ \\ Renata Albuquerque Ribeiro ${ }^{3}$ \\ Tássia Camila de Oliveira Carvalho ${ }^{4}$
}

\begin{abstract}
Resumo
A Política Externa brasileira tem entrado cada vez mais no cotidiano da sociedade, passando a ser entendida como política pública. Nesse sentido, com o objetivo de contribuir com métodos de pesquisa para uma maior apropriação da política externa enquanto objeto de análise, o presente artigo, por meio da análise do conteúdo de pronunciamentos oficiais, oferece mais um modelo analítico possível para a área. Apesar de ainda pouco explorada, a ferramenta aqui sugerida pretende analisar semelhanças ou contradições na fala dos líderes políticos que representam a política externa brasileira. Para isso foi criado um extenso banco de dados dos pronunciamentos oficiais dos presidentes brasileiros, a fim de investigar como as mudanças na política externa brasileira repercutem nos discursos oficiais em diferentes tópicos. Por meio do método aqui proposto, tem-se a intenção de tornar pública a ação e/ou intenção dos governos, bem como facilitar e estimular o uso da interpretação dos pronunciamentos oficiais para fins de pesquisa acadêmica. Inicialmente, são apresentados a perspectiva teórica utilizada, os conceitos aplicados e a construção da análise. Na parte empírica, ilustramos nosso argumento com um exemplo de aplicação do método, analisando o tratamento do tema "direitos humanos" nos vinte e oito pronunciamentos de lideranças brasileiras realizados em aberturas da Assembleia Geral das Nações Unidas. Como conclusões iniciais, ilustramos as potencialidades do método e sua funcionalidade para a análise da política externa brasileira.
\end{abstract}

Palavras-Chave: Política externa brasileira; pronunciamentos oficiais; análise de conteúdo.

\begin{abstract}
Brazilian Foreign Politics has come into the everyday life of Brazilian society, now being seen as public policy-making. Therefore, aiming at contributing with more adequate research methods to get a better comprehension of foreign politics as a research object, this essay uses content analysis of official statements to offer another analytical model to be used in this field. Although little explored, the tool herein suggested lends itself to the analysis of both similarities and contradictions in the speech of several political leaders who represent Brazilian Foreign Politics. In order to make such analysis possible, an extensive database was devised to store official presidential speeches, allowing for an investigation of how changes in foreign policy-making echoes in different aspects of such speeches. Through the use of the proposed method, we intend to turn public the action and/or the intention of governments, as well as facilitate and stimulate the use of content analysis when dealing with official speeches in academic research. First, theoretical perspective, applied concepts and the
\end{abstract}

\footnotetext{
${ }^{1}$ DOI deste artigo: $10.5380 /$ recp.v6i2.39039.

2 Doutoranda em Ciência Política pelo Instituto de Estudos Sociais e Políticos da Universidade do Estado do Rio de Janeiro (Iesp/UERJ) e pesquisadora do Laboratório de Análise Mundial, LABMUNDO. E mail: daniellecsilva87@gmail.com

${ }^{3}$ Doutoranda em Ciência Política pelo Instituto de Estudos Sociais e Políticos da Universidade do Estado do Rio de Janeiro (Iesp/UERJ) e pesquisadora do Laboratório de Análise Mundial, LABMUNDO. E mail: renataribeiro@iesp.uerj.br

${ }^{4}$ Cientista Política, Mestra em Administração e pesquisadora bolsista pela FAPERJ do Laboratório de Análise Mundial, LABMUNDO. E mail:tassiaurio@gmail.com
} 
making of the analysis will be presented. On the other hand, empirically, our point is illustrated by an example in which the method was applied to, through the analysis of twenty eight Brazilian leadership speeches delivered during the United Nation General Assembly, all revolving around the topic of "human rights". As initial conclusions, we show the potential of the method and its functionality when analysing Brazilian Foreign Politics.

Keywords: Brazilian Foreign Policy; official statements; content analysis.

\section{Resumen}

En los últimos años, la política exterior brasileña ha entrado cada vez más en la vida cotidiana de la sociedad, llegando a ser entendida como una política pública. En este marco, con el fin de contribuir con los métodos de investigación susceptibles de ofrecer una mejor apropiación de la política exterior en cuanto objeto de análisis, este trabajo, mediante el análisis de contenido de declaraciones oficiales, propone un modelo de análisis posible para esta área. Aunque poco explorada, la herramienta aquí sugerida tiene como objetivo examinar las similitudes o contradicciones en el discurso de los líderes políticos que representan la política exterior brasileña. Para ello, hemos creado una amplia base de datos con las declaraciones oficiales de los presidentes de Brasil con el fin de investigar cómo los cambios en la política exterior de Brasil impactan en los discursos oficiales sobre de diferentes temas y cuestiones. Mediante este método, además de tornar pública la acción y / o la intención de los gobiernos, buscamos facilitar y fomentar el uso de la interpretación de las declaraciones oficiales en el marco de la investigación académica. En primer lugar, presentamos la perspectiva teórica, los conceptos aplicados y la construcción del análisis. En la parte empírica, ilustramos nuestra discusión con un ejemplo de aplicación del método, estudiando el tema "derechos humanos" en veintiocho declaraciones de líderes brasileños en ceremonias de apertura de la Asamblea General de las Naciones Unidas. Finalmente, en las conclusiones, resaltamos el potencial de este método y su funcionalidad para el análisis de la política exterior brasileña.

Palabras-clave: política exterior brasileña; declaraciones oficiales; análisis de contenido.

\section{INTRODUÇÃO}

A Política Externa brasileira tem entrado cada vez mais no cotidiano da sociedade. Se houve um tempo em que se julgavam as decisões políticas internacionais como de domínio apenas do Estado, atualmente há uma inegável e crescente demanda por maior participação social nas decisões internas e externas. Milani e Pinheiro (2013), ao apontar para esse processo de transição, ressaltam a necessidade de construção de novos marcos interpretativos por parte da academia como, por exemplo, deslocar a percepção da política externa como uma política de Estado, para percebê-la como uma política pública. Esse novo olhar que aproxima o doméstico do externo, nos faz refletir sobre os processos desta transição e se ela é notável no decorrer do tempo. É possível identificar uma mudança substancial capaz de atribuir novos significados à Política Externa Brasileira?

Sob a influência weberiana, entendemos que o "fazer ciência" é sempre um esforço interpretativo e incompleto de determinada realidade. Neste sentido, o presente artigo objetiva contribuir para novas análises interpretativas sobre a política externa por meio da elaboração de uma metodologia que permita analisar o conteúdo de pronunciamentos 
oficiais, iniciada a partir da criação de um extenso banco de dados de pronunciamentos dos presidentes brasileiros do período da Nova República (de Tancredo Neves) ao período atual (Dilma Rousseff). As amostras integradas ao banco de dados são, principalmente, os "pronunciamentos oficiais" disponíveis no período delimitado, agregando, sempre que possível, entrevistas com os presidentes e ministros e outros atores relevantes.

A metodologia adotada para a catalogação e, posteriormente, categorização dos pronunciamentos é de viés qualitativo por meio do software NVivo 10, que permite filtrar e classificar os pronunciamentos. O software, ademais, permite que o material seja reunido sob um tema, ideia ou tópico por meio de um processo de codificação. Apesar das ferramentas quantitativas do software, não temos como objetivo tornar a análise quantitativa um mero recurso mecanizado, excluindo a análise subjetiva e interpretativa. Por esta razão, a linha teórica que modela nossa proposta de análise traz uma perspectiva crítica aos modelos behavioristas de "fazer ciência". Utilizando como base teórica o trabalho de Laurence Bardin (1979), entendemos que a "análise de conteúdo" tem por princípio uma abordagem investigativa que não negligencia as influências sócio espaciais e o contexto em que determinado discurso se insere, bem como não negligencia a própria capacidade de influência do pesquisador sobre este processo. A essa concepção teórica, reconhecemos a importância da vertente da Análise de Discurso que considera a fala ou o pronunciamento como uma interface tridimensional: qualquer "evento" discursivo deve ser considerado simultaneamente um texto, um exemplo de prática discursiva e um exemplo de prática social (FAIRCLOUGH, 2001, p.22). Já que o discurso, no caso o pronunciamento, é socialmente construído e, portanto, moldado pelos processos da prática social, podemos utilizá-lo como ferramenta de análise da ação dos atores encarregados da prática política. Portanto, também consideramos o discurso [nesse caso não cabe a substituição de discurso por pronunciamento] como uma estrutura social por meio da qual podemos identificar as ideias e os interesses dos atores, levando em consideração também quem discursa, para quem se discursa, em qual lugar e com qual objetivo se discursa.

Sendo assim, apresentamos a perspectiva teórica aqui utilizada a fim de definir tanto nossa abordagem metodológica, quanto os conceitos aplicados nesse trabalho. Tal explanação faz-se necessária, sobretudo, para suprir possíveis carências metodológicas e teóricas ao longo do trabalho. Não temos por objetivo trazer definições absolutas, mas apenas aquelas capazes de atender às demandas aqui postas. Após a abordagem teórica, apresentamos a parte prática, explanando sobre as etapas do trabalho desde a seleção dos discursos às interpretações e exemplos de primeiros resultados após o tratamento dos dados. 
Por fim, apresentamos nossas conclusões iniciais visando a contribuir para o debate metodológico e teórico por meio de novas análises capazes de redirecionar o olhar para a atual percepção que a Análise de Política Externa vem adquirindo. A apresentação, neste sentido, da Análise de Conteúdo de pronunciamentos oficiais objetiva, sobretudo, ilustrar as potencialidades do método e demonstrar a sua funcionalidade para a análise da política externa brasileira ${ }^{5}$.

\section{ABORDAGEM TEÓRICA: A ESCOLHA PELA ANÁLISE DE CONTEÚDO}

Faz-se necessário definir as bases teóricas que permitem dar sentido à parte prática da pesquisa, justificando a utilização da Análise de Conteúdo como base teórica para análise do material proposto. Para isso, foi preciso igualmente, diferenciar os aportes metodológicos da Análise de Discurso e da Análise de Conteúdo.

Para Bardin (1979), a Análise de Conteúdo abrange as iniciativas de explicitação, sistematização e expressão do conteúdo de mensagens, com a finalidade de efetuarem-se deduções lógicas e justificadas a respeito da origem dessas mensagens (quem as emitiu, em que contexto e/ou quais efeitos se pretende causar por meio delas). Como se pode perceber pela definição apresentada, a autora defende que a Análise de Conteúdo oscila entre os dois pólos que envolvem a investigação científica: o rigor da objetividade e a fecundidade da subjetividade, resultando na elaboração de indicadores quantitativos e/ou qualitativos que devem levar o pesquisador a uma segunda leitura da comunicação, baseado na dedução. Essa nova compreensão do material textual, que vem substituir a leitura dita "normal" por parte do leigo, visa a revelar o que está subentendido na mensagem. Logo, a Análise de Conteúdo pode ser utilizada, nas Ciências Sociais, tanto em pesquisas de cunho quantitativo, quanto qualitativo (BARDIN, 1979, p.4).

O desenvolvimento da Análise de Conteúdo como procedimento de exame de comunicações de cunho jornalístico se deu no início do século XX nos Estados Unidos da América, durante cerca de 40 anos. Porém, Bardin (1979) afirma que no período seguinte à II Guerra Mundial, a Análise de Conteúdo caiu no descrédito e no desinteresse dos

\footnotetext{
${ }^{5}$ Posteriormente a elaboração do presente artigo, reconhecemos a existência de outras pesquisas na área de análise de conteúdo aplicadas ao campo da análise de política externa, como por exemplo, o trabalho de Castro Santos (2010) sobre as bases da doutrina da política externa norte-americana relacionada à segurança e à exportação da democracia. A autora utiliza Análise de Conteúdo quantitativa e qualitativa dos discursos de Presidentes e Secretários de Estado dos EUA para analisar os pilares da referida doutrina. Acreditamos, portanto que tal metodologia pode e deve ser utilizada a fim de analisar a política externa brasileira.
} 
investigadores, cujos trabalhos não obtiveram o alcance e nem o mérito esperado. Nos anos 1950, houve uma revitalização da mesma, que passou a ser novamente discutida em vários congressos sobre Psicolinguística de forma mais aberta e diversificada. Foram também desenvolvidas novas perspectivas metodológicas e surgiram dessa vez novos questionamentos por outras áreas das ciências sociais além do Jornalismo, como a Etnologia, a História, a Psiquiatria, a Psicanálise, a Linguística, a Sociologia, a Psicologia e a Ciência Política, cada uma propondo sua contribuição (CAPPELLE, LOPES MELO e GONÇALVES, 2003, p.4-5).

Com a acentuação do debate entre a pesquisa quantitativa e qualitativa nas Ciências Sociais, passa-se a discutir também a utilização da Análise de Conteúdo tanto por uma, quanto por outra abordagem. Nesse caso, as análises quantitativas, por um lado, preocupamse com a frequência com que surgem determinados elementos nas comunicações, interessadas no desenvolvimento de novas formas de procedimento para mensurar as significações identificadas. Por outro lado, os enfoques qualitativos voltam sua atenção para a presença ou para a ausência de uma característica, ou conjunto de características, nas mensagens analisadas, na busca por ultrapassar o alcance meramente descritivo das técnicas quantitativas, atingindo interpretações mais profundas com base na inferência (BARDIN, 1979; MINAYO, 2000, apud CAPPELLE, LOPES MELO e GONÇALVES, 2003, p.5). Assim como toda técnica de investigação procura proporcionar aos investigadores um meio de apreender as relações sociais em determinados espaços de uma forma apropriada ao tipo de problema de pesquisa proposto, a Análise de Conteúdo visa, portanto, "a ultrapassar o nível do senso comum e do subjetivismo na interpretação e alcançar uma vigilância crítica em relação à comunicação de documentos, textos literários, biografias entrevistas ou observação" (MINAYO, 2000 apud CAPPELLE, LOPES MELO e GONÇALVES, 2003, p.5).

Já a Análise de Discurso surge como disciplina na década de 1960, na França, com os marxistas Michel Pêcheux, filósofo que considera a análise de discurso uma ruptura epistemológica com a ideologia dominante nas ciências humanas (o marxismo), e Jean Dubois, linguista que pensa a análise de discurso como a passagem natural do estudo das palavras ao estudo do enunciado (dentro da linguística). Se desde então já é possível notar certa indefinição sobre o conceito, com o passar do tempo e a popularização do campo por outras áreas do conhecimento, a dificuldade de definição conceitual aumentou ainda mais. De acordo com Nogueira (2001), devido à ampla influência que a temática vem adquirindo em diferentes campos, torna-se difícil estabelecer uma única e simples definição de Análise 
de Discurso. Em essência, a Análise de Discurso buscaria responder à seguinte questão: o que este texto quer diz̧er? Uma definição mais genérica a definiria como um "estudo aprofundado da linguagem de que se utiliza, procurando a identificação de padrões” (NOGUEIRA, 2001, p. 23). Em relação aos procedimentos de análise, a Análise de Discurso tem a noção de funcionamento como central, levando o analista a compreendê-lo pela observação dos processos e mecanismos de constituição de sentidos e de sujeitos, utilizando a paráfrase e a metáfora como elementos que permitem certo grau de operacionalização dos conceitos (ORLANDI, 2013, p.77).

De forma objetiva, pode-se dizer que o aspecto fundamental da Análise de Discurso está na compreensão do significado do texto por meio da análise de seus sentidos ocultos, não ditos ou inconscientes, bem como da formação social e a ideologia de quem fala. Além disso, a Análise do Discurso parte dos pressupostos de que o sentido de uma palavra expressa as posições ideológicas em jogo no processo sócio histórico em que são produzidas (CAPPELLE, LOPES MELO e GONÇALVES, 2003, p.10). Tal abordagem liga-se a uma tradição epistemológica que, em tese, contesta a perspectiva positivista de ciência e percebe a linguagem como capaz de construir objetos, sujeitos, subjetividade e a própria personalidade de um indivíduo.

Transpondo para o campo das relações internacionais, Milliken (1999, p. 226-227) vê a Análise de Discurso como um programa de pesquisa emergente engajando uma comunidade de acadêmicos que careciam de um paradigma de ciência. Tal "escola de discurso" é regularmente caracterizada como uma ciência desviante ou marginal por causa da falta de teorias testáveis ou análises empíricas, além de adotar uma postura "anticientificista" que rejeita critérios e metodologias de análise, levando tais pesquisadores a um projeto pós-positivista de Análise de Discurso.

Em comparação com a Análise de Discurso, a Análise de Conteúdo tem como enfoque um objeto muito mais específico e direto: não se buscam padrões sociais, interpretações, mas tão somente revelar intenções e diretrizes políticas e suas possíveis relações com os contextos históricos e conjunturais. A Análise de Conteúdo parte da estrutura do texto para interpretá-lo, considerando-o como ilustração de uma situação limitada ao seu próprio contexto. Deste modo, a abordagem pela qual optamos trabalhar metodologicamente diferencia-se em diversos aspectos da Análise de Discurso, sendo a principal distinção o fato de nossa abordagem não se vincular a uma análise da linguagem, 
mas sim a um processo conjuntural, trabalhando com os produtos dos textos e buscando compreendê-los por meio de seu conteúdo.

Cabe destacar também que nossa proposta de Análise de Conteúdo dos pronunciamentos oficiais se diferencia da epistemologia discursiva proposta pela vertente pós-estruturalistas das relações internacionais, centrada na ideia de que a prática discursiva implicaria uma ligação ontológica entre a política e a identidade. Assim, por meio do discurso da política externa que a identidade do ator político surgiria (HANSEN, 2006, p.19). O foco analítico estaria na construção do discurso da identidade ao mesmo tempo constitutivo da política externa e produto dela, o qual não é o objetivo da nossa metodologia, orientada a visualizar, por meio da prática discursiva, a visão e a ação dos atores na formulação da política externa.

Mesmo não optando em seguir a vertente da Análise de Discurso, nossa proposta de Análise de Conteúdo de pronunciamentos oficiais não deixa de lado questões trabalhadas por essa vertente, tais como a capacidade dos discursos serem sistemas de significação que caracterizam determinado contexto social e político e operam para dar às pessoas conhecimento sobre a realidade social (MILLIKEN, 1999, p.231). Mesmo não nos aprofundando na análise das estruturas de significação que constroem realidades sociais, conforme o entendimento da vertente construtivista de significado (pessoas constroem o significado das coisas, usando sistema de signos), também consideramos a produtividade do discurso, ou seja, que os discursos definem os sujeitos autorizados a falar e a agir. Além disso, apoiamos a posição de Milliken a respeito dos analistas de discurso e de seus críticos terem em comum a defesa de que o debate não deve consistir em fundamentar uma pesquisa empírica rigorosa ou em desenvolver teorias melhores, mas sim em utilizar diversas abordagens analíticas que veem o objeto "discurso" como forma de interpretação de um contexto social, político, cultural ou econômico. Por certo, a metodologia aqui proposta também procura desempenhar uma análise que possa ser usada como método investigativo das mudanças sociais e políticas dos governos em relação à política externa. Contudo, para identificar tais mudanças, nossa atenção encontra-se voltada para a quantificação da presença e a identificação da ausência de determinados temas no conteúdo dos pronunciamentos de atores oficiais dos governos, juntamente com a contextualização histórica, social e política e com a interpretação subjetiva dos pesquisadores.

Assim, a preocupação da presente pesquisa não é com a semântica ou com os diversos significados encrustados nos discursos, mas sim em realizar por meio da Análise de Conteúdo de pronunciamentos oficiais o levantamento das informações, propriedades e 
peculiaridades presentes nos pronunciamentos em prol da Análise de Política Externa, auxiliando tanto na construção da realidade política, social e econômica da política externa quanto para fundamentação das pesquisas por meio de material empírico quantitativo e qualitativo. Para nós, o pronunciamento oficial, ou "discurso", não possui uma precedência ontológica sobre a dimensão material da histórica, mas se insere na realidade material enquanto peça de evidência capaz de dialogar dialeticamente com esta realidade. A seguir demonstramos como essas abordagens e definições guiaram a realização da parte prática do trabalho.

\section{A PESQUISA EMPÍRICA}

De acordo com Bardin, a pesquisa da Análise de Conteúdo divide-se em três fases: a pré-análise que corresponde à leitura flutuante, referenciação dos índices e a elaboração de indicadores, à organização do material como a escolha dos documentos e objetivos; a exploração do material, a fase mais longa e complexa com a classificação e codificação das fontes; e o tratamento dos resultados, por meio da inferência e interpretação. Além disso, a autora esclarece a importância da fase de codificação. Segundo Holsti, "a codificação é o processo pelo qual os dados brutos são transformados sistematicamente e agregados em unidades, as quais permitem uma descrição exata das características pertinentes do conteúdo" (HOLSTI, 1969 apud BARDIN, 1979, p. 133). É nela que são feitos recortes em unidades de contexto e de registro, sendo os requisitos para uma boa categorização a exclusão mútua, homogeneidade, pertinência, objetividade e fidelidade e produtividade. Para codificar é necessário definir o elemento básico de análise ou onde aparece o termo procurado. Essas são as unidades de registro. Nesse momento é importante definir também as unidades de contexto, pois é o contexto que ajuda a compreender a unidade de registro, por exemplo:

Quadro 1 - Exemplo aplicado do modelo proposto por Bardin.

\begin{tabular}{|c|c|c|c|c|}
\hline Tema & Categorias & Subcategorias & $\begin{array}{l}\text { Unidades de } \\
\text { registro }\end{array}$ & Unidades de contexto \\
\hline 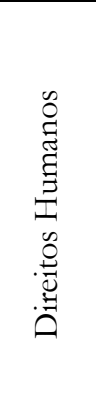 & $\begin{array}{l}\text { Respeito aos } \\
\text { direitos } \\
\text { humanos }\end{array}$ & $\begin{array}{c}\text { Direitos dos } \\
\text { indígenas; direitos } \\
\text { das mulheres; } \\
\text { direitos das } \\
\text { crianças; igualdade } \\
\text { racial. }\end{array}$ & $\begin{array}{c}\text { Termos: indígenas; } \\
\text { mulheres; crianças; } \\
\text { igualdade racial; } \\
\text { respeito. }\end{array}$ & $\begin{array}{l}\text { Ex 1. Collor, 1990: “As afrontas aos } \\
\text { direitos humanos devem ser } \\
\text { denunciadas e combatidas com igual } \\
\text { vigor, (...). Neste campo, uma das } \\
\text { minhas preocupações fundamentais é } \\
\text { com a preservação da vida e dos } \\
\text { costumes das comunidades indígenas } \\
\text { do Brasil. Para tanto, meu Governo } \\
\text { tomou medidas drásticas que }\end{array}$ \\
\hline
\end{tabular}




\begin{tabular}{|c|c|c|c|c|}
\hline & & & & $\begin{array}{l}\text { constituem atitude de respeito } \\
\text { absoluto e de proteção intransigente } \\
\text { dos direitos de nossos índios." }\end{array}$ \\
\hline & & & & $\begin{array}{l}\text { Ex 2. Lula, 2005: "A preocupação com } \\
\text { os direitos das mulheres e com a } \\
\text { promoção da igualdade racial permeia } \\
\text { todas as nossas políticas públicas. (...) } \\
\text { Exemplifico com algo que me } \\
\text { emociona profundamente: negros e } \\
\text { indios pobres, oriundos da escola } \\
\text { pública, agora podem entrar na } \\
\text { universidade, graça ao nosso } \\
\text { programa de cotas étnicas e de apoio } \\
\text { financeiro aos alunos carentes". }\end{array}$ \\
\hline 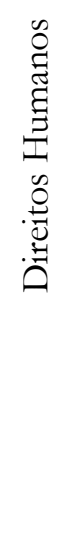 & $\begin{array}{l}\text { Autodetermi } \\
\text { nação dos } \\
\text { povos }\end{array}$ & Sem subcategoria & $\begin{array}{l}\text { Termos: povos; } \\
\text { reconhecimento; } \\
\text { autodeterminação. }\end{array}$ & $\begin{array}{l}\text { Ex. FHC, 2002: “O Brasil apoia a } \\
\text { criação de um Estado palestino } \\
\text { democrático, seguro } \\
\text { economicamente viável, assim como o } \\
\text { direito do povo palestino à } \\
\text { autodeterminação. O Brasil também } \\
\text { defende o direito à existência do } \\
\text { Estado de Israel dentro de fronteiras } \\
\text { reconhecidas e o de seu povo viver em } \\
\text { segurança. Ambas são condições } \\
\text { essenciais para uma paz duradoura no } \\
\text { Oriente Médio". }\end{array}$ \\
\hline
\end{tabular}

Fonte: Elaboração própria.

Seguindo essa ordem, portanto, temos:

TEMA $>$ CATEGORIAS $>$ SUBCATEGORIAS $>$ UNIDADES DE REGISTRO > UNIDADES DE

\section{CONTEXTO}

No período de pré-análise, foi realizada uma extensa coleta de pronunciamentos oficiais para a construção do banco de dados, seguidos pela organização desse material de acordo com o governo presidencial e o ano. As amostras que integram o banco de dados são principalmente pronunciamentos oficiais de presidentes e/ou ministros, e possivelmente outros atores governamentais relevantes. A principal fonte de tais materiais é o site da Biblioteca da Presidência da República ${ }^{6}$, o qual tem arquivados inúmeros pronunciamentos oficiais de vários ex-presidentes da República, além dos da atual presidência, assim como coletâneas de pronunciamentos organizadas pela Fundação Alexandre Gusmão,

\footnotetext{
${ }^{6}$ Site da Biblioteca da Presidência da República: http://www.biblioteca.presidencia.gov.br/pagina-inicial-3
} 
disponibilizadas em seu site 7 . Já a metodologia adotada para a catalogação e, posteriormente, categorização dos pronunciamentos é de âmbito qualitativo por meio do uso do software de análise NVivo $10^{8}$ para filtragem e classificação dos pronunciamentos.

O trabalho de análise de conteúdo desses pronunciamentos é temático, ou seja, busca-se no conteúdo das fontes (dos pronunciamentos) uma posição afirmativa ou sentença específica sobre determinado tema (direitos humanos, cooperação, meio ambiente, entre outros). Com isso, o primeiro passo é identificar quais pronunciamentos possuem referência aos temas escolhidos, o que é obtido por meio de uma busca simples por palavras. Aqueles pronunciamentos que apresentam alguma referência são agregados em um nố designado de acordo com o tema (exemplo: nó direitos humanos, nó cooperação, etc.). Uma vez identificado quais fontes possuem menção ao tema, passa-se a codificar as particularidades desse tema em subnós ${ }^{10}$, ou subcategorias. Para isso é necessário ler cada fonte agregada no nó do tema. Não há uma regra geral para o estabelecimento das categorias, as mesmas dependem do tema principal a ser analisado, do objeto da pesquisa e da subjetividade do pesquisador. Por exemplo, o nó direitos humanos agrega entre seus subnós categorias como: respeito aos direitos humanos, autodeterminação dos povos, instituições internacionais, direito das mulheres, direitos indígenas, entre outros.

Após a categorização das fontes, pode-se realizar a exploração do material, à qual é feita por meio da quantificação dos subnós, na contabilização da manifestação dos tópicos relevantes ao tema pesquisado de acordo com os governos presidenciais. Dessa forma, é possível identificar quais foram os tópicos mais importantes, os menos frequentes e até mesmo as singularidades de cada um dos governos, para, posteriormente, realizar uma comparação dessa quantificação entre os governos. Destaca-se que tal quantificação dos dados não negligencia a análise qualitativa dos mesmos, pois cabe ao pesquisador, em sua subjetividade, fazer as deduções dos resultados, realizando a interpretação dos trechos

\footnotetext{
${ }^{7}$ Site da FUNAG: http://www.funag.gov.br/pt_br/

${ }^{8}$ NVivo 10 é um software de análise de dados qualitativos e mistos (conteúdo textual, sons, imagens) por meio do qual é possível filtrar e classificar as fontes de pesquisa em diversos formatos (doc, docx, pdf, rtf, txt, etc.) e armazenar todos os dados todos em um único arquivo. O referido software foi selecionado devido a sua ampla capacidade de armazenamento, as várias ferramentas de análise quantitativa, como a contagem de palavras, e também por organizar o conteúdo qualitativo, permitindo a realização de uma análise qualitativa bem estruturada.
}

${ }^{9}$ Nó é a ferramenta do programa NVivo 10 para a codificação dos dados de acordo, por exemplo, com um tema.

${ }^{10}$ Os subnós são as codificações feitas a partir de um nó já existente. 
codificados, relacionando-os, por exemplo, com a conjuntura da política doméstica ou da política externa, com as diretrizes políticas e econômicas do período de governo estudado, etc. $O$ processo de quantificação das categorias consiste no instrumento pelo qual o pesquisador identifica a presença ou ausência dos tópicos importantes para o tema pesquisado, possibilitando também uma melhor visualização dos dados por meio de tabelas e gráficos. Uma vez que a categorização realizada pelo software não só quantifica como também armazena o pronunciamento em referências textuais, é possível analisar qualitativamente o conteúdo da mensagem e, portanto, seu contexto histórico, político, econômico e social. Após essa descrição das etapas de análise, cabe exemplificar a prática da pesquisa aqui descrita.

\section{EXEMPLIFICANDO: ANÁLISE DE CONTEÚDO NA POLÍTICA EXTERNA BRASILEIRA DE DIREITOS HUMANOS}

À guisa de ilustrar a aplicação da metodologia aqui apresentada, utilizamos como exemplo um modelo de Análise de Conteúdo ${ }^{11}$ tendo como fontes principais os vinte e oito pronunciamentos tanto de Presidentes quanto de Ministros das Relações Exteriores realizados na abertura da Assembleia Geral das Nações Unidas ${ }^{12}$ durante o período pósredemocratização do Brasil (1985-2013). A importância de tais pronunciamentos está no fato de seu conteúdo apresentar os parâmetros da política externa brasileira do governo no poder, explicitar a posição do Estado perante as questões internacionalmente pertinentes e também por este ser o principal instrumento para anunciar inflexões, protestos e descontentamentos e, igualmente, expor ideias, conflitos, apoios e acusações perante a comunidade internacional, podendo assim produzir impactos positivos ou negativos nas relações com os demais Estados.

Para analisar o conteúdo de tais pronunciamentos, primeiramente as fontes, já inseridas no software NVivo 10, foram codificadas de acordo com o nome do Presidente

\footnotetext{
11 A pesquisa que serve de exemplo para o presente artigo pode ser vista na íntegra no trabalho "Política Externa Brasileira de Direitos Humanos: analisando a trajetória dos direitos humanos após a redemocratização por meio da Análise de Conteúdo de Discurso", de autoria de Danielle Costa da Silva, apresentada no GT Estudos de Política Externa do IX Encontro da ABCP. Disponível em: http://www.encontroabcp2014.cienciapolitica.org.br/resources/anais/14/1403668736_ARQUIVO_Politica ExternaBrasileiradeDireitosHumanos-artigoABCP.pdf .

12 A fonte principal de análise é o livro “O Brasil nas Nações Unidas 1946-2011” (2012), organizado por Luiz Felipe de Seixas Corrêa e editado pela Fundação Alexandre Gusmão. Para complementar o livro, somam-se os discursos da Presidente Dilma Rousseff disponíveis na página de Presidência da República, disponíveis em: http://www2.planalto.gov.br/acompanhe-o-planalto/discursos\#b_start=0 .
} 
correspondente aos anos de seu período de governo, mesmo que alguns pronunciamentos tenham sido feitos por Vice-Presidentes ou por Ministros das Relações Exteriores. Por meio da leitura do material, foram identificados os trechos referentes ao campo dos direitos humanos e, em seguida, feita uma análise categorial desse conteúdo objetivando identificar quais foram os tópicos que tiveram maior destaque ou que mereceram atenção especial pelos governos democráticos. Essa análise categorial foi projetada, inicialmente, identificando o aparecimento de termos-chave (por exemplo, democracia, desenvolvimento, nomes de tratados ou instituições internacionais) nos trechos referentes aos direitos humanos, os quais serviram de base para a criação das categorias. Conforme explicitado em nossa abordagem teórica, a presença de tais categorias é considerada como representativa da concepção de quem discursa (no caso, do governo) sobre o tema abordado. Em seguida à criação das categorias, a etapa seguinte consiste em enquadrá-las nos trechos textuais de acordo com seu conteúdo. Ressalta-se que algumas referências textuais podem ser inseridas em mais de uma categoria. Em nosso modelo, as categorias identificadas foram:

Quadro 2 - Categorias identificadas no nó direitos humanos.

\begin{tabular}{|c|c|}
\hline CATEGORIA & DESCRIÇÃO \\
\hline Respeito aos direitos humanos & $\begin{array}{c}\text { Afirmações sobre respeito, promoção, proteção dos direitos } \\
\text { humanos e contra a sua violação, em sua totalidade (direitos civis, } \\
\text { políticos, sociais e econômicos). }\end{array}$ \\
\hline Instituições e Tratados Internacionais & $\begin{array}{c}\text { Agrega referências ao papel das instituições e órgãos } \\
\text { internacionais, principalmente ONU, em relação aos direitos } \\
\text { humanos. }\end{array}$ \\
\hline Autodeterminação dos povos & $\begin{array}{c}\text { Afirmações relacionadas à autodeterminação dos povos, como nos } \\
\text { casos do conflito Palestina-Israel, autonomia e não ingerência em } \\
\text { países em conflito. }\end{array}$ \\
\hline Democracia & $\begin{array}{c}\text { Afirmações sobre a relação entre direitos humanos e a democracia } \\
\text { como forma de governo, garantidora da liberdade e dos direitos } \\
\text { fundamentais das pessoas. }\end{array}$ \\
\hline Discriminação & $\begin{array}{c}\text { Refere-se às situações de segregação praticadas por Estados } \\
\text { (apartheid), condenações às formas de discriminação, racismo e } \\
\text { xenofobia. }\end{array}$ \\
\hline Desenvolvimento & $\begin{array}{l}\text { Relação entre a promoção do desenvolvimento e a garantia dos } \\
\text { direitos humanos. }\end{array}$ \\
\hline Combate à fome e à pobreza & $\begin{array}{l}\text { Considerações de tais tópicos como sendo política de promoção } \\
\text { dos direitos humanos. }\end{array}$ \\
\hline Terrorismo & $\begin{array}{l}\text { Afirmação de condenação ao terrorismo, visto como sendo uma } \\
\text { ameaça à segurança da humanidade. }\end{array}$ \\
\hline $\begin{array}{l}\text { Direitos das mulheres, igualdade } \\
\text { racial, direito das crianças e direitos } \\
\text { dos indígenas. }\end{array}$ & $\begin{array}{c}\text { Aglomera as menções a tais direitos específicos, tanto no âmbito } \\
\text { das instituições internacionais quanto em nível doméstico } \\
\text { (políticas públicas de promoção da igualdade e garantia de } \\
\text { direitos). }\end{array}$ \\
\hline
\end{tabular}

Fonte: Elaboração própria. 
A partir dessa etapa, foi possível realizar a análise categorial do conteúdo dos pronunciamentos, identificando a frequência de aparição de tais categorias em cada um dos governos. Com tal quantificação categorial, por fim, é possível a construção de gráficos ${ }^{13}$. De modo ilustrativo, demonstramos alguns resultados obtidos no caso da análise quantitativa e qualitativa dos pronunciamentos do governo Lula (2003-2010) ${ }^{14}$.

Dentre os resultados obtidos na pesquisa dos pronunciamentos oficiais do recorte aqui analisado, alguns resultados podem ser empiricamente demonstrados. Os dados apontaram para a política externa do governo Lula (2004-2010), como responsável por reforçar a participação do Brasil nos órgãos de proteção dos direitos humanos da ONU, além de ter colaborado com a busca de solução para problemas econômicos e sociais em nível global ao relacionar intensamente a questão do desenvolvimento com a dos direitos humanos. A própria política externa do governo Lula foi formulada e realizada em prol do processo de desenvolvimento nacional do Brasil e também de outros países em desenvolvimento.

Gráfico 1 - Tópicos Referentes aos Direitos Humanos no Governo Lula TÓPICOS REFERENTES AOS DIREITOS HUMANOS NO GOVERNO LULA (2003-2010)

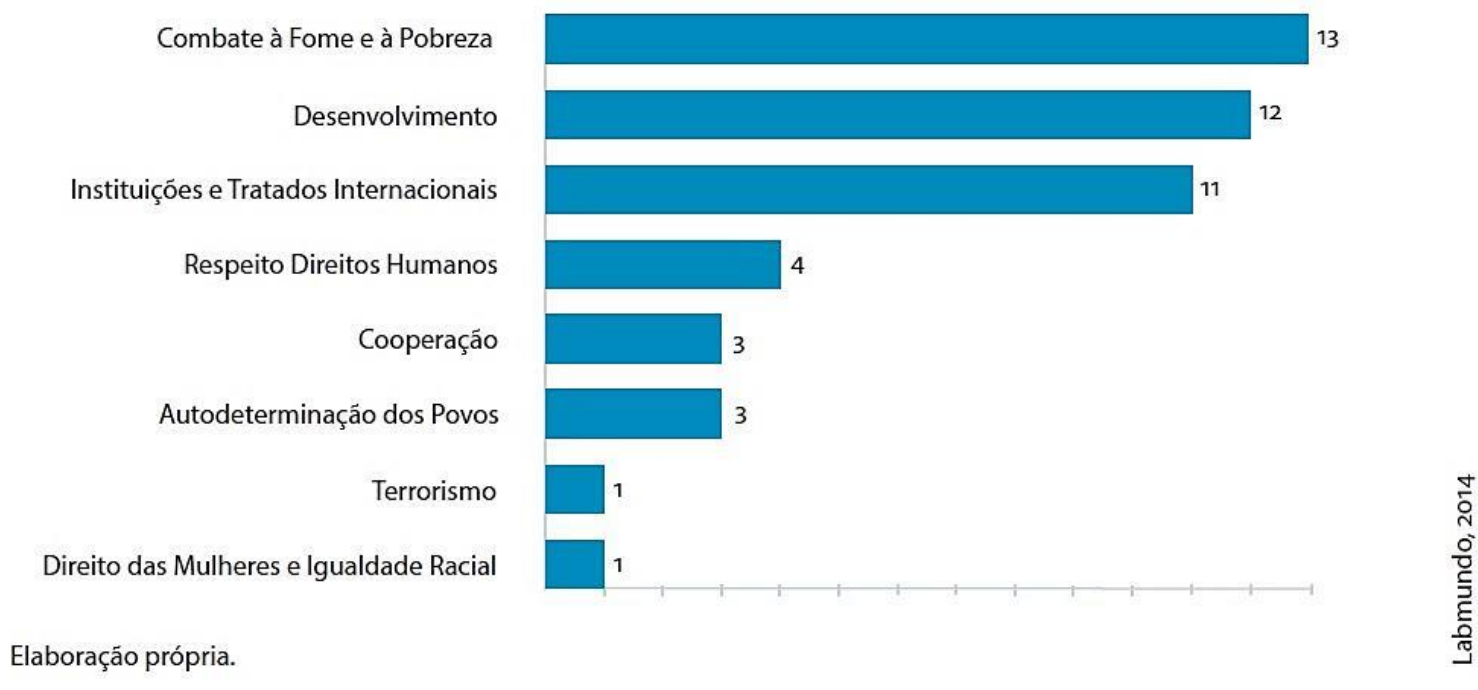

Os três tópicos com os maiores números de referências têm, de alguma forma, relação entre si: o combate à fome e à pobreza, o desenvolvimento e as instituições internacionais. A partir do governo Lula, a referência explícita ao combate à fome e à pobreza

\footnotetext{
13 As datas entre parênteses ao lado dos nomes dos Presidentes nos gráficos se referem às datas dos discursos por esse governo na Assembleia Geral das Nações Unidas.

${ }^{14}$ A mesma análise foi feita para os governos Sarney, Collor, Itamar Franco e FHC, vide Costa da Silva (2014).
} 
extrema são considerados tópico de importância vital ao campo dos direitos humanos e também ao desenvolvimento, uma vez que o combate à fome foi uma das principais características da política interna de Lula, sendo a mesma, portanto, incorporada à política externa desse governo. A própria defesa da erradicação da fome, em âmbito doméstico e externo, está baseada naquele que seria o mais fundamental dos direitos humanos: o direito à vida.

Ao mencionar que o Brasil estava instaurando um modelo de desenvolvimento que unia estabilidade econômica com inclusão social, o governo Lula defendeu uma ordem mundial à qual o comércio deveria servir à promoção do desenvolvimento social, principalmente na luta contra a fome e a pobreza, em complementação ao trabalho já desenvolvido pela Assembleia Geral, como a convocação de várias Conferências temáticas (direitos humanos, meio ambiente, direitos da mulher, discriminação racial). Para isso, o governo se engajou na proposta da criação de um Fundo Mundial de Combate à Fome e também a criação no âmbito da ONU de um Comitê Mundial de Combate à Fome, o qual seria integrado por chefes de governo. Também houve o pedido de reforço e aperfeiçoamento dos mecanismos da ONU na esfera dos direitos humanos, apoiando a criação do Conselho de Direitos Humanos, baseado nos princípios da universalidade, do diálogo e da não seletividade. Ainda nesse tópico, o governo Lula destaca o papel da cooperação internacional na esfera dos direitos humanos, principalmente entre países em desenvolvimento, para a solução de problemas socioeconômicos e de assistência humanitária, com ambos se orientando pelo princípio da responsabilidade coletiva, da não intervenção em assuntos internos, mas também acompanhada da ideia da "não indiferença".

A categorização permite, ademais, uma análise comparativa dos pronunciamentos de cada governo a partir das categorias definidas dentro do respectivo tema.

Nesse caso, comparamos a adesão ao termo "desenvolvimento": 
Gráfico 2 - Categoria Desenvolvimento

\section{CATEGORIA DESENVOLVIMENTO}

Comparação entre governos

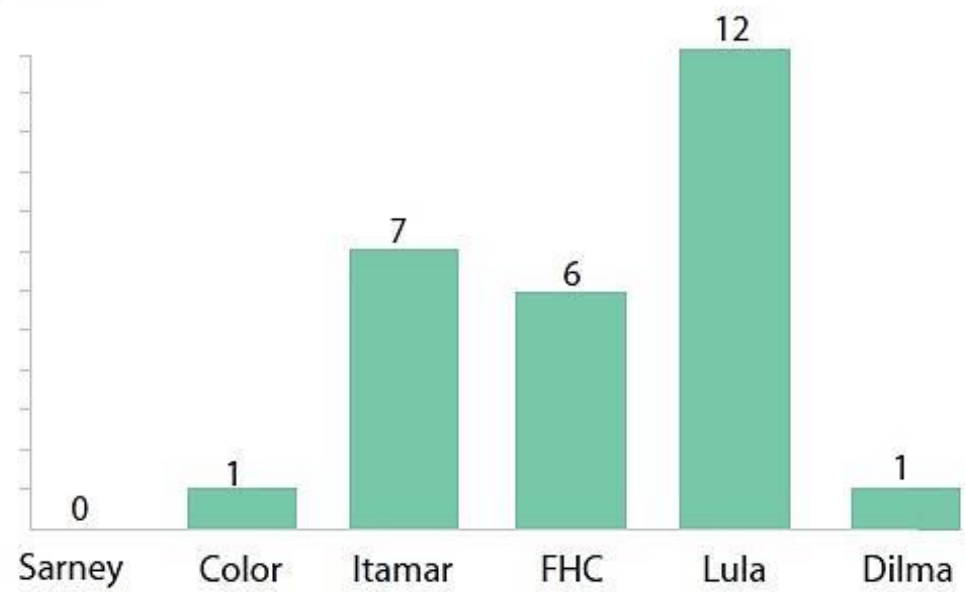

Fonte: Elaboraçăo própria

Da completa ausência do tópico nos pronunciamentos de Sarney e de uma singela menção em Collor, o desenvolvimento em sua relação com os direitos humanos ganha força primeiramente nos pronunciamentos do governo Itamar Franco, em seu sentido de promover benfeitorias para o bem estar dos indivíduos e nos benefícios que a democracia juntamente com o desenvolvimento traria para o campo dos direitos humanos, com o conjunto democracia, direitos humanos e desenvolvimento se tornando indissociáveis. No governo FHC, mantêm-se a defesa do desenvolvimento, mas baseado no que o governo chama de "concepção moderna de desenvolvimento", promovendo os direitos humanos, tanto civis e políticos, sociais e culturais, apesar de ter sido o viés econômico do desenvolvimento o que mais se sobressaiu durante essas referências, como a defesa da eliminação das práticas e barreiras protecionistas para garantir acesso aos mercados e melhorar as condições do combate às doenças, exemplificado pelo caso do Brasil em relação à quebra de patentes e à produção de remédios genéricos, buscando disponibilizá-los de forma mais barata à população brasileira.

A partir do governo Lula, nota-se a referência explícita ao combate à fome e à pobreza extrema como sendo tópicos de importância vital no campo dos direitos humanos e também ao desenvolvimento. Cabe aqui destacar a relação entre o papel de Celso Amorim como Ministro das Relações Exteriores com o aparecimento do tópico do desenvolvimento tanto durante o governo de Itamar Franco quanto do governo do presidente Lula. Dando continuidade ao modelo de desenvolvimento defendido pelo seu antecessor e também do compromisso com o combate à fome e à pobreza, o governo Dilma Rousseff ressaltou o 
papel das mulheres, especialmente como principais gerenciadoras dos recursos de programas de distribuição de renda, somando-se também a luta pela igualdade de direitos e contra a discriminação e a violência.

A categoria "desenvolvimento" é bem representativa da necessidade de, no processo de categorização do conteúdo dos pronunciamentos oficiais, olhar para o contexto histórico ao qual o discurso remete. Assim, “desenvolvimento" seria uma chave genérica que se diferencia de acordo com o enfoque de cada governo. Conforme enfatizado no tópico 1 desse artigo, a quantificação das procedências presentes nos discursos, em si, não deve negligenciar essa realidade, servindo como um artifício analítico que deve ser problematizado em seu contexto.

\section{CONCLUSÕES INICIAIS}

O principal objetivo do presente artigo é contribuir para o debate metodológico e teórico de novas análises capazes de redirecionar o olhar para a atual conjuntura da Análise de Política Externa. A apresentação, neste sentido, da Análise de Conteúdo de pronunciamentos oficiais objetiva exatamente ilustrar as potencialidades do método e demonstrar a sua funcionalidade para a análise da política externa tanto na Ciência Política quanto nas Relações Internacionais.

A quantificação do conteúdo dos pronunciamentos possibilita ao pesquisador não apenas um material empírico, mas uma forma de identificar quais tópicos/categorias aparecem, são destacados ou negligenciados, auxiliando-o, por exemplo, na construção dos marcos políticos de um determinado governo, em um determinado tema. O trabalho de leitura dos pronunciamentos e de categorização dos trechos também acaba por familiarizar ainda mais o pesquisador com seu objeto de pesquisa, dando-lhe um conhecimento mais a fundo sobre o tema, guiando a análise qualitativa dos dados.

Por se tratar de uma pesquisa ainda em andamento, cabe destacar que novas formas de interpretar os conteúdos dos pronunciamentos assim como a exploração de outras ferramentas disponíveis do software NVivo10, tais quais a frequência de palavras e o agrupamento de palavras próximas pelo formato de "nuvem", podem vir a ser amplamente utilizadas nessa análise, contribuindo ainda mais para o fornecimento de material empírico para as pesquisas.

Visto isso, a partir dos argumentos e dos exemplos apresentados aqui, pode-se concluir que é eficaz a aplicabilidade do método Análise de Conteúdo para a captação dos 
conteúdos presentes nos pronunciamentos presidenciais oficiais então analisados. Por meio desse método, foi possível identificar as especificidades, as mudanças e as semelhanças dos pronunciamentos oficiais dos governos federais no âmbito das Nações Unidas e, consequentemente, da atuação do Estado brasileiro perante a política externa de direitos humanos.

Se a Política externa é fruto da forte relação entre o doméstico e o internacional e, se caminha para uma percepção sobre a necessidade de diálogo com a sociedade, buscando colocar-se como uma política pública, a análise dos conteúdos dos pronunciamentos oficiais nos permite então perceber as controvérsias presentes na fala e intenção dos representantes e atores responsáveis por dar vOz ao Estado brasileiro nos foros internacionais, eventos, e organizações internacionais. Sendo assim, nossa proposta de análise de conteúdo, que une o quantitativo com o qualitativo, se apresenta como meio eficiente e adequando que se associa a outros métodos (análise histórica, estudos de caso, pesquisa comparativa) no sentido de fortalecer e encorpar os estudos de política externa no Brasil.

\section{REFERÊNCIAS}

BARDIN, Laurence. 1979. Análise de Conteúdo. São Paulo: Edições 70.

CAPPELLE, Mônica Carvalho Alves; LOPES MELO, Marlene Catarina de Oliveira; GONÇALVES, Carlos Alberto. 2003. “Análise de Conteúdo e Análise de Discurso nas Ciências Sociais". In. Organizações Rurais e Agroindustriais - Revista de Administração da UFLA. Volume $5, \mathrm{n}^{\mathrm{o}} 1$.

CASTRO SANTOS, Maria Helena. 2010. "Exportação de democracia na política externa norte-americana no pós Guerra Fria: doutrinas e o uso da força”. In. Revista Brasileira de Política Internacional. 53(1): pp.157-191.

CORRÊAA, Luiz Felipe de Seixas (ORG.). 2012. O Brasil nas Naçoes Unidas: 1946-2011. Brasília: Fundação Alexandre Gusmão.

COSTA DA SILVA, Danielle. 2014. "Política Externa Brasileira de Direitos Humanos: analisando a trajetória dos direitos humanos após a redemocratização por meio da análise de conteúdo de discurso". In. Anais Eletrônicos do IX Encontro da Associação Brasileira de Ciência Política.
Brasília.
Disponível
em:

http://www.encontroabcp2014.cienciapolitica.org.br/resources/anais/14/1403668736_A

RQUIVO_PoliticaExternaBrasileiradeDireitosHumanos-artigoABCP.pdf.

FAIRCLOUGH, Norman. 2001. [1992]. Discurso e Mudança Social. Brasília: Editora UnB. 
HANSEN, Lene. "Discourse analysis, identity, and foreign policy". In. Security as practice: discourse analysis and the Bosnian War. Nova York: Routledge, 2006, cap.2, pp. 15-32.

MILANI, Carlos R. S.; PINHEIRO, Letícia. 2013. "Política Externa Brasileira: Os Desafios de sua Caracterização como Política Pública". In. Contexto Internacional. Rio de Janeiro, vol. $35, n^{\circ} 1$, janeiro/junho, p. 11-41.

MILLIKEN, Jennifer. 1999. "The Study of Discourse in International Relations: A Critique of Research and Methods". In. European Journal of International Relations. Vol. 5:225, pp. 225254.

NOGUEIRA, Conceição. “A Análise do Discurso”. 2001. In. ALMEIDA, Leandro S. e FERNANDES, Eugénia M. (Edts). Métodos e técnicas de avaliação: novos contributos para a prática e investigação. Braga: CEEP.

ORLANDI, Eni P. 2013 [1999]. Análise de Discurso: Princípios e Procedimentos. 11ª Edição. Campinas: Pontes Editores.

PÊCHEUX, Michel. 2012 [1983]. O discurso: estrutura ou acontecimento. 6ª Edição. Campinas: Pontes Editores. 